\title{
頭部 CT 骨条件でみられる内頸動脈サイフォン部の 石灰化の意義の検討
}

\author{
松本 英之 濱口 浩敏 中山 貴博 \\ 小田 哲也 五十川孝志 今福一郎
}

\begin{abstract}
要旨：頭部 CT 骨条件では一部の症例で内頸動脈サイフォン部に石灰化が観察される. しかし病的意義は不明な 点が多く,この石灰化を頭部 MRA と頸動脈超音波の所見と比較した. 対象は脳血管障害と診断したまたはうたがっ た患者 112 例である. 石灰化を形状により 4 段階に分類し, 頭部 MRA での同部位の狭窄度および頸動脈超音波で の max IMT と比較したところ, 有意な相関関係をみとめた. 近年の PACS 技術の発達により DICOM viewer 上で の骨条件への変換は容易となった. 石灰化の程度から内頸動脈サイフォン部と総頸動脈分岐部の動脈硬化を即座に 簡便に推定でき，内頸動脈の石灰化は虚血性脳血管障害の診療上，注目すべき項目の1つと考える.
\end{abstract}

(臨床神経, 48：114-119, 2008)

Key words：頭部CT，内頸動脈，石灰化，動脈硬化，脳血管障害

はじめに

虚血性脳血管障害の診療に当たり，脳血管の動脈硬化を評 価することは重要な因子の 1 つである. 近年は, 脳血管評価の ゴールドスタンダードである脳血管造影検査をおこなわずと も, 頭頸部 MR Angiography, 頭頸部 CT Angiography, 頸動 脈超音波, 経頭蓋超音波などをもちいることにより,より非侵 襲的に動脈硬化を評価することができる。 また 2005 年 10 月 11 日から発症後 3 時間以内の虚血性脳血管障害超急性期に rt-PA（アルテプラーゼ）による血栓溶解療法が認可され, 病 歴聴取, 診察, 臨床検查などにより，短時間のうちにより多く の情報をえることが必要となった，その際 early CT signs(早 期虚血性変化) の存在 ${ }^{12)}$ が適応の決め手となり, 単純頭部 CT の読影の重要性が再認識されている.

一方, 単純頭部 CT では, 一般に内頸動脈の動脈硬化を評価 することは周囲の構造物により困難である.われわれは, 一部 の症例に頭部 CT 骨条件にて内頸動脈サイフォン部（鞍上 部一屈曲部一海綿静脈洞部付近）を中心として石灰化を確認 できることに注目した，今回われわれは頭部 CT 骨条件にて みられる内頸動脈石灰化の病的意義について, 稱血管障害の 日常診療に扔いて非侵襲的かつ簡便であり, 血管系の評価に 標準的にもちいられる頭部 MRA および頸動脈超音波3 と比 較検討した。
方 法

A. 対象

2005 年 4 月から 2006 年 1 月までの間, 当院に入院し脳血 管障害と診断または脳血管障害をうたがった患者のうち，頭 部 CT, 頭部 MRA, 頸動脈超音波を施行した患者 112 例 (男 68 例, 女 44 例, $30 \sim 97$ 歳, $70.3 \pm 12.5$ 歳 (平均士標準偏差)) を対象とした。 また高血圧, 糖尿病, 高脂血症, 喫煙の有無を 病歴聴取, 血液検查により確認した. 高血圧, 糖尿病, 高脂血 症はWHO 分類基準にしたがい, 各々最高血圧 $140 \mathrm{mmHg}$ 以上または最小血圧 $90 \mathrm{mmHg}$ 以上, 早朝空腹時血糖が 126 $\mathrm{mg} / \mathrm{d} l$ または HbAlc $6.5 \%$ 以上，血清総コレステロール 220 $\mathrm{mg} / \mathrm{d} l$ 以上または LDL コレステロール $140 \mathrm{mg} / \mathrm{d} l$ 以上とし た.

B. 頭部 CT 骨条件での内頸動脈サイフォン部の石灰化の 評価

頭部 CT は東芝メディカルシステムズ社製 Aquilion TSX$101 \mathrm{~A}$ を使用した. 当院では頭部 CT 画像を電子カルテ上で簡 単に骨条件 (Window level/width 400/2,500) に変換すること ができる (Fig. 1). その条件下で左右それぞれの内頸動脈の石

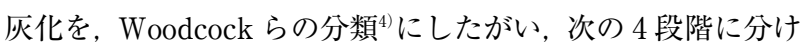
て評価した；0. 正常 (石灰化なし)，1. 軽度石灰化（薄くかつ 連続性なし)，2. 中等度石灰化 (薄くかつ連続性あり，または 厚くかつ連続性なし)，3. 高度石灰化(厚くかつ連続性あり), とした（Fig. 2). 


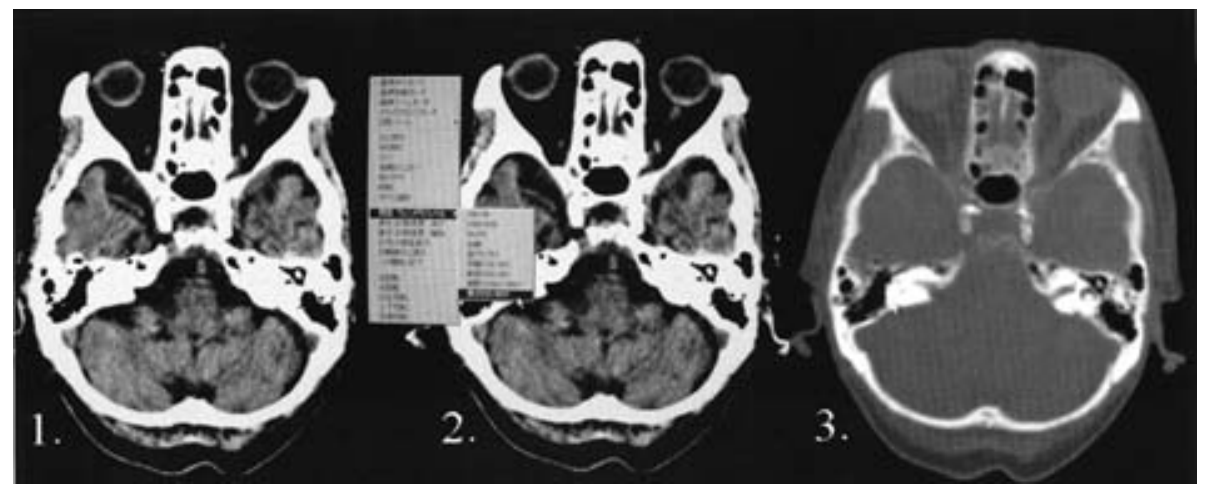

Fig. 1 Conversion plain condition into bone condition on DICOM viewer of brain CT. On DICOM viewer, clinicians can convert plain condition (1) into bone condition (3) on brain CT immediately and easily by clicking command on the computer screen (2).

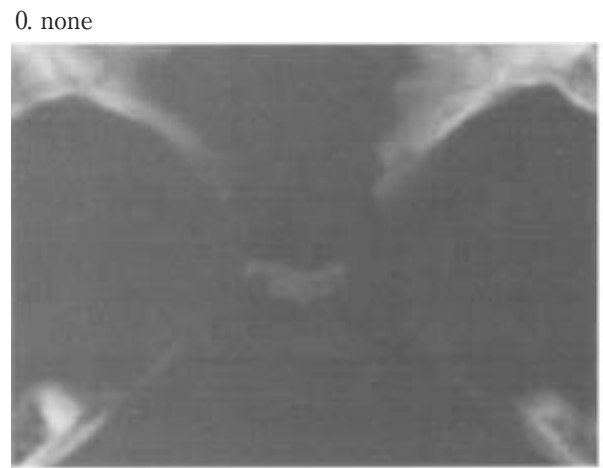

1. mild

2. moderate

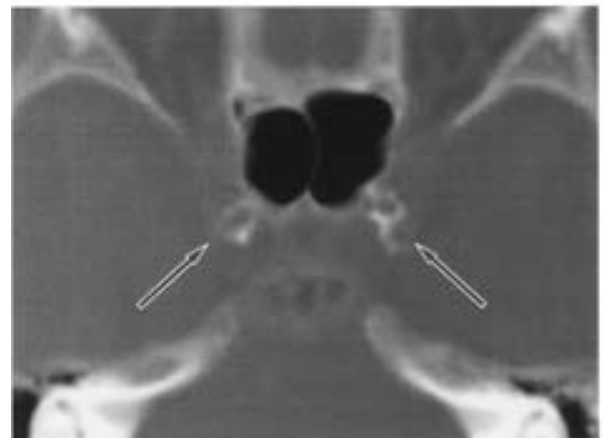

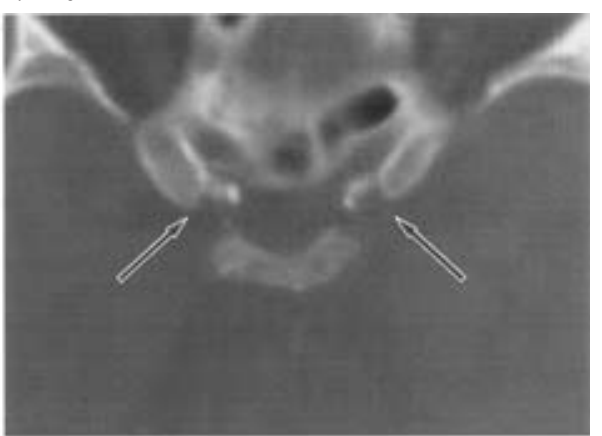

3. severe

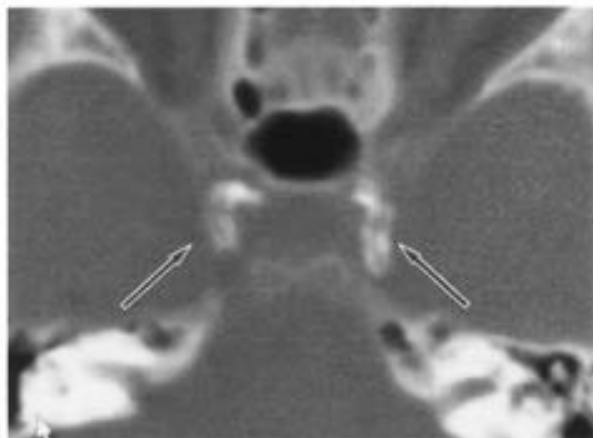

Fig. 2 Classification of carotid siphon calcification on bone condition of brain CT Arrow: calcification

C. 頭部 MRA での内頸動脈サイフォン部の狭窄度の評価 頭部 MRA は GE 社 製 Signa Horizon LX Echo Speed 1.5T を使用し，三次元タイムオブフライト法(3D TOF 法)をもち いて左右それぞれの内頸動脈サイフォン部の狭窄度を, Uehara らの分類 ${ }^{5) 6}$ にししだい, 次の 4 段階で評価した；0. 正常 (狭窄なし), 1. 軽度狭窄 ( $50 \%$ 未満の狭窄), 2. 中等度狭窄 (50\% 以上の狭窄), 3. 高度狭窄（非連続性に描出）とした. 頭部 MRA にて内頸動脈がまったく描出されないものや, 内 頸動脈サイフォン部以外の部位に狭窄があるためにサイフォ
ン部が描出不良のばあいは, 動脈硬化の評価としては適当で はないと判断し, 評価対象外とした.

D. 頸動脈超音波での総頸動脈および内頸動脈起始部の評 価

頸動脈超音波は東芝メディカルシステムズ社製 SSA-700A またはSSA-390A を使用し, B モード断層法をもちいて, 左右 の総頸動脈および内頸動脈起始部を観察し, 頸動脈エコーに よる動脈硬化性病変評価のガイドライン（案）に基づき3), 同 部位の far wall での intima-media thickness (以下 IMT) の最 
Table 1 Characteristics in 112 patients

\begin{tabular}{l|c|c|c|c|c|c|c}
\hline \multicolumn{1}{c|}{ Disorders } & Cases & $\begin{array}{c}\text { Age } \\
(\text { Mean } \pm \text { SD })\end{array}$ & $\begin{array}{c}\text { Sex } \\
(\mathrm{M} / \mathrm{F})\end{array}$ & Hypertension & Diabetes mellitus & Hyperlipidemia & Smoking \\
\hline Cerebral infarction & & & & & & & \\
Atherothrombotic & 38 & $67.2 \pm 12.0$ & $28 / 10$ & $26(68.4 \%)$ & $14(36.8 \%)$ & $10(26.3 \%)$ & $28(73.7 \%)$ \\
Lacunar & 19 & $70.7 \pm 11.7$ & $11 / 8$ & $16(84.2 \%)$ & $8(42.1 \%)$ & $4(21.1 \%)$ & $11(57.9 \%)$ \\
Cardioembolic & 15 & $74.7 \pm 8.4$ & $10 / 5$ & $6(40.0 \%)$ & $3(20.0 \%)$ & $3(20.0 \%)$ & $9(60.0 \%)$ \\
$\quad$ Arterial dissection & 2 & $40.0 \pm 5.7$ & $1 / 1$ & $0(0.0 \%)$ & $0(0.0 \%)$ & $0(0.0 \%)$ & $1(50.0 \%)$ \\
TIAs & 7 & $77.7 \pm 13.9$ & $3 / 4$ & $5(71.4 \%)$ & $3(42.9 \%)$ & $1(14.3 \%)$ & $2(28.6 \%)$ \\
Cerebral hemorrhage & 2 & $81.0 \pm 2.8$ & $2 / 0$ & $2(100 \%)$ & $0(0.0 \%)$ & $1(50.0 \%)$ & $1(50.0 \%)$ \\
Others & 29 & $71.3 \pm 12.5$ & $13 / 16$ & $13(44.8 \%)$ & $9(31.0 \%)$ & $4(13.8 \%)$ & $13(44.8 \%)$ \\
\hline
\end{tabular}

TIAs: transient ischemic attacks, SD: standard deviation, M: male, F: Female

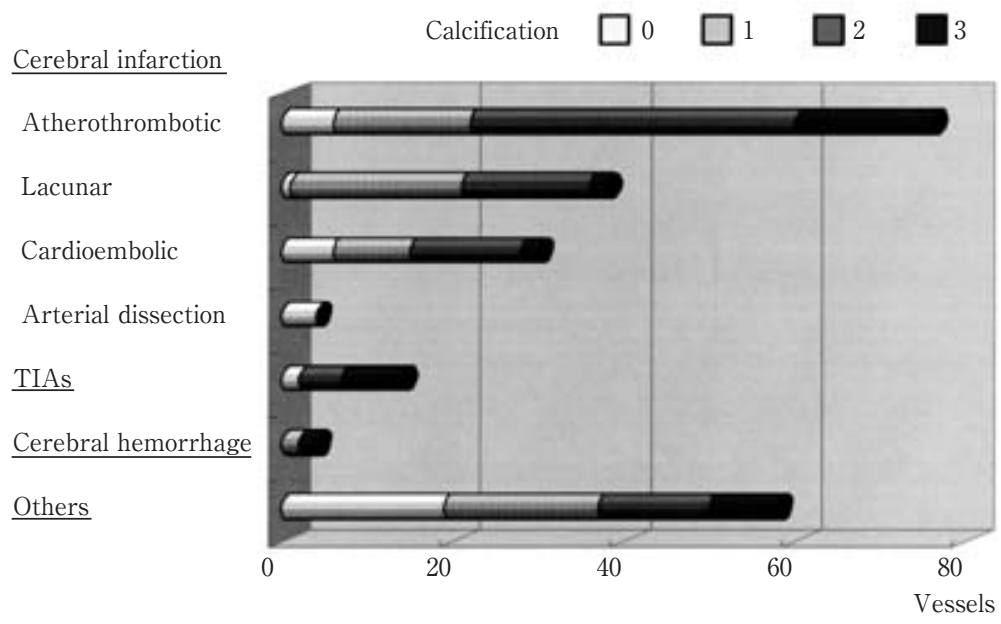

Fig. 3 Degree of calcification of each disorder

大值を $\max \mathrm{IMT}(\mathrm{mm})$ とした. また $\max \mathrm{IMT} 1.1 \mathrm{~mm}$ 以上 をプラークと定義し，プラークを有するばあいに動脈硬化あ りと規定した. ただし, $\max$ IMT $1.1 \mathrm{~mm}$ 以上が明らかに動脈 硬化以外の要因からなると考えられるばあいには，動脈硬化 の評価としては適当ではないと判断し, 評価対象外とした.

E. 検討項目

上記 $\mathrm{B}, \mathrm{C}$ の評価に関しては, 臨床および検査の情報のない 状態で, 2 名の神経内科医がそれぞれ別々に評価し, 評価のこ となるものは議論の上, 狭窄度を決定した. 以下の 3 項目に関 して検討した.

1. 頭部 CT 石灰化と頭部 MRA 狭窄度の比較

2. 頭部 CT 石灰化と頸動脈超音波 max IMT の比較

3. 頭部 CT 石灰化が動脈硬化（max IMT $1.1 \mathrm{~mm}$ 以上）を 検出する感度, 特異度, 陽性適中率

F. 統計処理

上記の 1 と 2 の項目に関しては, Spearmanの順位相関係 数検定により関連の有無を検討した. $\mathrm{P}<0.05$ を有意である と判定した.
結果

対象患者 112 例の患者背景を Table 1 に示す．内訳はアテ ローム血栓性脳梗塞 38 例, ラクナ梗塞 19 例, 心原性脳塞栓症 15 例, 椎骨動脈解離による脳梗塞 2 例, 一過性脳虚血発作 7 例, 脳出血 2 例と脳血管障害が計 83 例であり, その他 29 例 （末梢性めまいなど）であった．左右の内頸動脈 224 本の内訳 は，頭部 CT での内頸動脈石灰化については，0. 正常：36 本, 1 . 軽度石灰化 $: 65$ 本, 2. 中等度石灰化 $: 84$ 本, 3. 高度石 灰化：37 本であった。病型別の石灰化の程度について, Fig. 3 に示す.とくにアテローム血栓性脳梗塞では, 高度石灰化お よび中等度石灰化の占める割合が高いことがわかる．頭部 MRA での同部位の狭窄度については, 評価対象外に該当す るものが 12 本あり, 212 本を検討し，0.正常 : 26 本，1. 軽度 狭窄 : 120 本, 2 . 中等度狭窄 : 44 本, 3. 高度狭窄 : 22 本で あった. 頸動脈超音波での max IMTについては, 評価対象外 に該当する血管はみとめなかった。

1. 頭部 CT 石灰化と頭部 MRA 狭窄度の比較

Fig. 4 に結果を示す. 頭部 CT での内頸動脈石灰化と頭部 MRA での同部位の狭窄度の間に, 有意な相関関係をみとめ 
た. 相関係数 $\mathrm{r}_{\mathrm{s}}=0.54, \mathrm{P}<0.01$ であった.

2. 頭部 CT 石灰化と頸動脈超音波 max IMT の比較

それぞれの内頸動脈石灰化に対する頸動脈超音波での $\max I M T$ (平均士標準偏差, 範囲 $(\mathrm{mm})$ ) は, 0. 正常 : $1.03 \pm$ $0.64(0.4 \sim 2.8)$, 1. 軽度石灰化 : $1.65 \pm 0.83(0.5 \sim 4.1)$, 2. 中等 度石灰化 : $2.03 \pm 0.83(0.8 \sim 4.1), 3$. 高度石灰化 : $2.81 \pm 1.15$ （0.7〜6.5）であった（Fig. 5). 頭部 CT での内頸動脈石灰化と 頸動脈超音波での max IMT の間に，有意な相関関係をみと めた． 相関係数 $\mathrm{r}_{\mathrm{s}}=0.56, \mathrm{P}<0.01$ であった.

3. 頭部 CT 石灰化が動脈硬化を検出する感度, 特異度, 陽 性適中率

それぞれ，感度 $93.3 \%$, 特異度 $47.3 \%$, 陽性適中率 $84.2 \%$ であった

\section{考察}

今回の検討では, 頭部 CT 骨条件でみられる内頸動脈サイ フォン部の石灰化は, 頭部 MRA での同部位の狭窄度および 頸動脈超音波での総頸動脈から内頸動脈の max IMT と有意

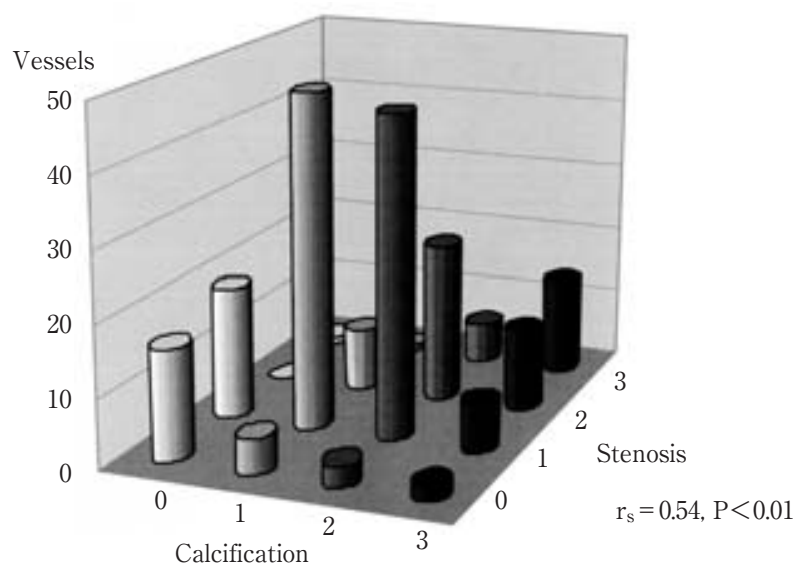

Fig. 4 Significant correlation between calcification and stenosis
な関連をみとめた。このことから頭部 CT 骨条件での内頸動 脈石灰化をみとめたばあい, その程度に応じて, 同部位の狭窄 や，総頸動脈から内頸動脈にかけての動脈硬化をうたがうこ とができる，具体的には内頸動脈石灰化と max IMT の関係 から， 0 (石灰化なし)では動脈硬化がみられないことが多く, 1 (軽度石灰化) では $1.1 \sim 2.0 \mathrm{~mm}$ 程度, 2 (中等度石灰化) で は $2.0 \mathrm{~mm}$ 前後, 3 (高度石灰化) では $3.0 \mathrm{~mm}$ 前後の動脈硬化 があるだろうと, 総頸動脈分岐部病変をおおよそ推定するこ ともできる. また, 頭部 CT 石灰化が動脈硬化を検出する感度 および陽性適中率は高く，とくに動脈硬化のスクリーニング として有用と考える。

一般的に内頸動脈の石灰化は, 大動脈・冠動脈などと同様 に粥状硬化にひき続き生じるものであり，動脈硬化の所見の 1 つと考えられている ${ }^{7) 8)}$. 石灰化はとくに内頸動脈サイフォ ン部に多く生じ910), この部位は剖検例でも病理学的に検討さ れており, 全身の動脈硬化の存在を示唆するとしている ${ }^{11)}$. ま たPtakらは, 本検討と同様に骨条件をもちいて, 内頸動脈サ イフォン部の石灰化と全身疾患の危険因子との関連を検討 し, 加齢, 高血圧, 糖尿病, 喫煙, 冠動脈疾患と関連があると 報告した ${ }^{12)}$.

Woodcock らも骨条件をもちいて, 内頸動脈サイフォン部 の石灰化を脳血管造影検査と比較検討している ${ }^{4}$. 骨条件での 高度の石灰化は脳血管造影検査での同部位の $50 \%$ 以上の狭 窄と関連があり, その陽性適中率は $86 \%$ としている. また通 常の単純頭部 CT では関連はみとめられず，陽性適中率も $11 \%$ であり, 骨条件の有用性を提唱している.内頸動脈の石 灰化の CT 值は通常 100 から 400 程度で，とくに石灰化の強 いものでは 1,000 に近いものも存在する ${ }^{13)}$ とされる. 石灰化の 程度を評価するためには, 骨条件などの十分な Window width をもつ撮像で評価する必要性があると考える。

頭部 MRA は狭窄病変を過大評価する性質があり，とくに サイフォン部は屈曲し周囲の構造物によるアーチファクトも あるため, この問題が顕著となりうる ${ }^{1415)}$. この点に関して は, 本検討では Uehara $ら^{5)}$ の頭部 MRA での狭窄度の分類に したがった．彼らはサイフォン部を頭部 MRA と脳血管造影

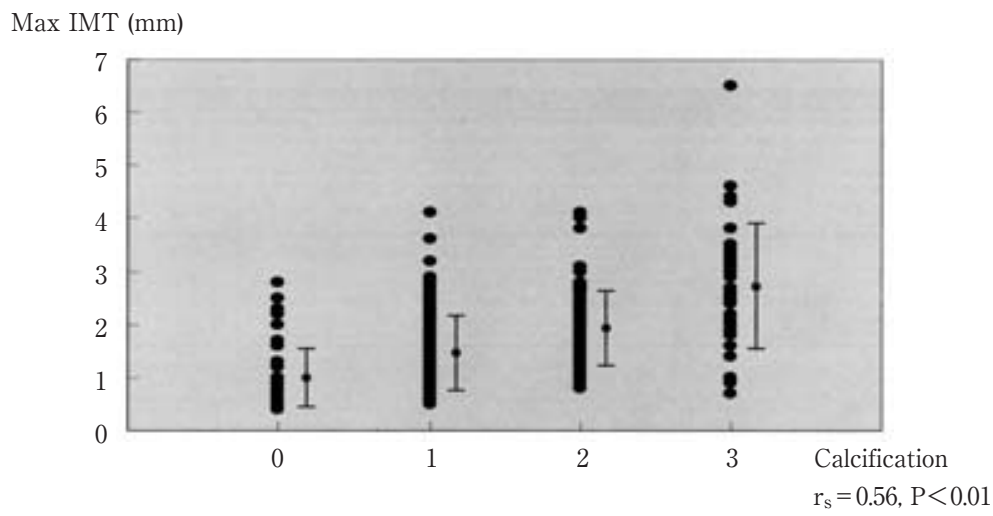

Fig. 5 Significant correlation between calcification and max IMT 
検査とで比較検討し，頭部 MRA は狭窄を過大評価するため 偽陽性率は高いものの，感度は $100 \%$, 特異度は $80 \%$ 以上で あり，血管評価に有用であるとしている.このため本検討の頭 部 MRA の狭窄度の分類は妥当なものと考えている.

本検討の特筆すべき点は, 内頸動脈サイフォン部の石灰化 を頸動脈超音波所見と比較した点であり，既報告は見当たら ない. 総頸動脈から内頸動脈の IMT 肥厚は, 虚血性脳血管障

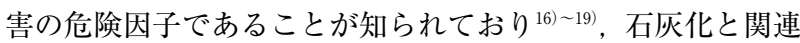
をみとめたことは重要な知見と考えられ，臨床的に有用と考 える.

一方, 本検討に打ける問題点は, 頭部 CT 骨条件の石灰化を 判定する際に, 症例毎のスライスレベルの違いが判定に関倸 している可能性がある点である。この問題はスライス方法を 統一することで軽減されるものと考えられ，スライス方法を あらかじめ放射線部と確認しておくことが必要である。

ここ数年, 医療機関のフィルムレス化のため, 医用画像管理 システム (picture archiving and communication system : PACS), 医用デジタル画像と通信 (digital imaging and communication in medicine：DICOM）をもちいた診療システム の導入が進んでいる2021). Window level/width の変換や骨条 件などの各種撮像条件への変換などの機能を持つものもあ り, 専門の技師や特殊な技術を要さずとも, 臨床医レベルで即 座に簡便に画像処理を㧍こなうことができ，骨条件撮影を追 加しなくとも DICOM viewer 上で骨条件画像をえることが 可能になってきている.このシステムは今後も更に普及する ことが期待され，即座に簡便に評価できる内頸動脈石灰化は， 虚血性脳血管障害の診療において注目すべき項目の 1 つと考 える.

本論文の要旨は第 47 回日本神経学会総会 $(2006$ 年 5 月 11 日, 東 京）で発表した。

\section{文献}

1) Tomura $\mathrm{N}$, Uemura $\mathrm{K}$, Inugami $\mathrm{A}$, et al: Early $\mathrm{CT}$ finding in cerebral infarction: obscuration of the lentiform nucleus. Radiology 1988; 168: 463-467

2) Truwit CL, Barkovich AJ, Gean-Marton A, et al: Loss of the insular ribbon: another early $\mathrm{CT}$ sign of acute middle cerebral artery infarction. Radiology 1990; 176: 801-806

3）日本脳神経超音波学会, 頸動脈エコー検査ガイドライン 作成委員会，動脈硬化性疾患のスクリーニング法に関す る研究班：頸動脈エコーによる動脈硬化性病変評価のガ イドライン (案). Neurosonology 2002；15：20-33

4) Woodcock RJ, Goldstein JH, Kallmes DF, et al: Angiographic correlation of $\mathrm{CT}$ calcification in the carotid siphon. Am J Neuroradol 1999; 20: 495—499

5) Uehara T, Mori E, Tabuchi M, et al: Detection of occlusive lesions in intracranial arteries by three-dimensional time-of-flight magnetic resonance angiography. Cerebrovasc Dis 1994; 4: 365-370

6) Uehara T, Tabuchi M, Mori E, et al: Evolving atheroscle- rosis at carotid and intracranial arteries in Japanese patients with ischemic heart disease: a 5-year longitudinal study with MR angiography. Eur J Neurol 2003; 10: 507512

7）桑原敬介, 北川一夫, 松本昌泰ら：10. 脳血管の動脈硬化 (血管壁の石灰化)。最新・分子動脈硬化学, 森崎信尋, 佐藤靖史, 山田信博ら 編, メディカルレビュー社, 東京, 2000, pp 115-126

8) Sohn YH, Cheon HY, Jeon P, et al: Clinical implication of cerebral artery calcification on Brain CT. Cerebrovasc Dis 2004; 18: 332-337

9) Boström K, Hassler O: Radiological study of arterial calcification, 2. Intracranial arteries. Neurology 1965; 15: $1168-1172$

10) Savy LE, Moseley IF: Intracranial arterial calcification and ectasia in visual failure. Br J Radiol 1996; 69: 394—401

11) Fisher CM, Gore I, Okabe N, et al: Calcification of the carotid siphon. Circulation 1965; 32: 538-548

12) Ptak T, Hunter GH, Avakian R, et al: Clinical significance of cavernous carotid calcifications encountered on head computed tomography scans perfomed on patients seen in the emergency depertment. J Comput Assist Tomogr 2003; 27: 505-509

13）竹上 徹, 本永貴郎, 島村 修ら：X 線 CT による内頸動 脈サイフォン部石灰化の評価. 京府医大誌 $1990 ； 99$ ： 1051-1056

14) Heiserman JE, Drayer BP, Keller PJ, et al: Intracranial vascular stenosis and occulusion: evaluation with threedimensional time-of-flight MR angiography. Radiology 1992; 185: 667-673

15) Korogi $Y$, Takahashi $M$, Nakagawa $T$, et al: Ingracranial vascular stenosis and occlusion: MR angiographic findings. Am J Neuroradiol 1997; 18: 135-143

16) Bots ML, Hoes AW, Koudstaal PJ, et al: Common carotid intima-media thickness and risk of stroke and myocardial infarction. The Rotterdom Study. Circulation 1997; 96: $1432-1437$

17) O'Leary DH, Polak JF, Kronmal RA, et al: Carotid- artery intima and media thickness as a risk factor for myocardial infarction and stroke in older adults. N Engl J Med 1999; 340: 14-22

18) Chambless LE, Folsom AR, Clegg LX, et al: Carotid wall thickness is predictive of incident clinical stroke. The Atherosclerosis Risk in Communities (ARIC) Study. Am J Epidemiol 2000; 151: 478—487

19) Kitamura $A$, Iso $H$, Imano $H$, et al: Carotid intima-media thickness and plaque characteristics as a risk factor for stroke in Japanese elderly men. Stroke 2004; 35: 27882794 
20) Inamura K, Konishi J, Nishitani H, et al: Status of PACS and technology assessment in Japan. Comput Meth Prog Biomed 2001; 66: 5-15
21) Inamura K, Kousaka S, Yamamoto $Y$, et al: PACS development in Asia. Comput Med Imaging Graph 2003; 27: $121-128$

\section{Abstract \\ Clinical and pathological significance of carotid siphon calcification observed on bone condition of brain CT

\author{
Hideyuki Matsumoto, M.D., Hirotoshi Hamaguchi, M.D., Takahiro Nakayama, M.D., \\ Tetsuya Oda, M.D., Takashi Ikagawa, M.D. and Ichiro Imafuku, M.D. \\ Department of Neurology, Yokohama Rosai Hospital
}

[Purpose] On plain brain computed tomography (CT), it is difficult to evaluate stenosis of internal carotid artery (ICA) because ICA is surrounded by structures, even though we can observe calcification of carotid siphon in some patients by using bone condition. However the pathologic significance has not been well known. We studied the pathologic significance of carotid siphon calcification observed on bone condition of brain CT. [Methods] A total of 112 patients who were diagnosed or suspected as cerebrovascular diseases were registered. We classified the calcification into four levels (none, mild, moderate, severe) based on the degree of calcification. Then we compared it with the degree of stenosis of carotid siphon seen on brain magnetic resonance angiography (MRA) and with max intima-medial thickness (IMT) from common carotid artery (CCA) to ICA on carotid ultrasonography. [Result] The mean \pm standard deviation of max IMT to none, mild, moderate and severe in the degree of calcification were $1.03 \pm 0.64$ (0.4-2.8), $1.65 \pm 0.83$ (0.5-4.1), $2.03 \pm 0.83$ (0.8-4.1) and $2.81 \pm 1.15$ (0.7-6.5) mm, respectively. The calcification on brain CT significantly correlated with the degree of stenosis on brain MRA and with max IMT on carotid ultrasonography. [Conclusion] The calcification of carotid siphon on bone condition of brain CT correlated with stenosis of the same portion and atherosclerosis of CCA bifurcation. Recently, on DICOM viewer, clinicians can convert plain condition into bone condition on brain CT due to popularization of PACS. We should pay attention to calcification of carotid siphon in patients with ischemic cerebrovascular diseases because we can estimate the atherosclerosis of both carotid siphon and CCA bifurcation easily and immediately.

(Clin Neurol, 48: 114-119, 2008)

Key words: computed tomography, internal carotid artery, calcification, atherosclerosis, stroke 